\title{
Satisfacción de cursos en AVA como estrategia de atención ante la contingencia covid-19
}

\section{Satisfaction of courses in AVA as a strategy of attention to the covid-19 contingency}

\author{
Heidi Angélica Salinas-Padilla ${ }^{1}$ \\ Juan José Díaz-Perera² \\ Mario Saucedo-Fernández ${ }^{3}$ \\ Santa del Carmen Herrera-Sánchez ${ }^{4}$ \\ Cd. Del Carmen, Campeche, México
}

\section{RESUMEN}

Actualmente las Universidades se enfrentan al reto de la continuidad de la educación superior ante la Contingencia de Salud existente por COVI-19 y el estado de Confinamiento que el Gobierno Federal ha impuesto a la población para minimizar las vías de contagio. En consecuencia, todo el sistema educativo tuvo que implementar la estrategia de Educación a distancia y en el caso de las Universidades en modalidad

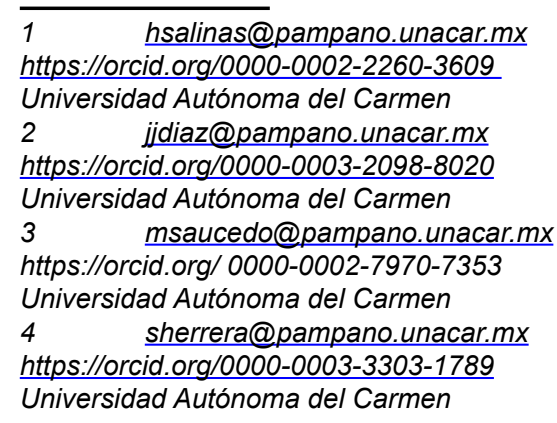

virtual. El presente documento plantea los resultados de investigación, el cual fue conocer el grado de satisfacción de los estudiantes en relación a sus cursos durante el ciclo febrero 2020, desarrollados en un ambiente virtual de aprendizaje como estrategia de atención ante la contingencia COVID-19 en la Universidad Autónoma del Carmen. Esta investigación fue de tipo exploratorio, se utilizó la herramienta de encuesta, con muestra no probabilística por conveniencia y estuvo constituida por 387 estudiantes. Parte de las opiniones que se obtuvieron fue un $83 \%$ de los estudiantes expreso satisfacción en relación al cambio de modalidad presencial a virtual y sobre la metodología de trabajo; el $92 \%$ de los estudiantes plateo que los profesores promovieron la autogestión, la investigación y responsabilidad en el desarrollo de sus actividades de aprendizaje, un $89 \%$ de 
los estudiantes consideran que los criterios de evaluación fueron implementados de acuerdo a lo que fue establecido en el programa inicial del curso.

PALABRAS CLAVE: AVA, Satisfacción, Estudiantes

\section{ABSTRAC}

Universities are currently facing the challenge of facing the continuity of higher education in the face of the existing Health Contingency by COVI-19 and the state of Confinement that the Federal Government has imposed on the population to minimize the routes of contagion. Consequently, the entire educational system had to implement the Distance Education strategy and in the case of the Universities in virtual mode. This document presents the research results was to know the degree of satisfaction of the students in relation to their courses during the February 2020 cycle, developed in a virtual learning environment as a strategy of attention to the COVID-19 contingency at the Universidad Autónoma del Carmen. This research was exploratory, the survey tool was used, with a non-probabilistic sample for convenience, it was constituted by 387 students. Part of the opinions that were obtained were $83 \%$ of the students expressed satisfaction in relation to the change from face-to-face to virtual mode and about the work methodology; $92 \%$ of the students stated that the teachers promoted self-management, research and responsibility in the development of their learning activities, $89 \%$ of the students consider that the evaluation criteria were implemented according to what was established in the initial course program.

KEYWORDS: AVA, Satisfaction, Students

\section{RESUMO}

Atualmente, as universidades enfrentam 0 desafio de enfrentar a continuidade do ensino superior diante da Contingência Sanitária existente pela COVI-19 e do estado de Confinamento que o Governo Federal impôs à população para minimizar as rotas de contágio. Consequentemente, todo o sistema educacional teve que implementar a estratégia de Educação a Distância e no caso das Universidades na modalidade virtual. Este documento apresenta os resultados da pesquisa foi conhecer o grau de satisfação dos alunos em relação aos seus cursos durante o ciclo de fevereiro de 2020, desenvolvido em um ambiente virtual de aprendizagem como estratégia de atenção à contingência COVID-19 na Universidad Autónoma del Carmen. A pesquisa foi exploratória, utilizou-se o instrumento survey, com amostra não probabilística por conveniência, foi constituída por 387 alunos. Parte das opiniões obtidas foi que $83 \%$ dos alunos expressaram satisfação em relação à mudança da modalidade presencial para a virtual e quanto à metodologia de trabalho; $92 \%$ dos alunos afirmaram que os professores promoveram a autogestão, a investigação e a responsabilidade no desenvolvimento das suas atividades de aprendizagem, $89 \%$ dos alunos consideram que os critérios de avaliação foram implementados de acordo com o estabelecido no programa de curso inicial.

PALAVRAS-CHAVE: AVA, Satisfação, Alunos

\section{DESARROLLO}

A finales del año 2019 la OMS confirmó la existencia de un nuevo virus COVID-19 que tuvo su origen principalmente en China, pero este virus no tardo demasiado en esparcirse y llegar a la mayoría de los países del mundo sin importar en que continente.

Hablar del virus SARCOV-2, más conocido como COVID-19, implica inevitablemente hacer referencia a las estrategias de contención que alrededor de 102 países han tenido que implementar para hacerle frente. En este sentido los países desarrollaron estrategias 
desde diversos escenarios que van en primera instancia desde el escenario de la salud, el económico y por supuesto el educativo.

México no fue la excepción, de esta manera el gobierno mexicano mediante la Secretaría de Salud, ordenó a la población en general a ingresar a confinamiento buscando preservar la salud de los mexicanos y disminuir los riesgos de contagios. De esta forma, ésta estrategia se convirtió en un elemento de impacto transversal para los demás sistemas en los que se encuentra organizado de manera gubernamental el país, e inevitablemente afectando de forma directa al sistema educativo (Fernández, Hernández, Nolasco, De la Rosa, Herrera, 2020).
La estrategia del Sistema Educativo Mexicano, fue la implementación de la educación a distancia, en formatos diversos que fueron desde la Televisión Educativa hasta la modalidad virtual. Sin embargo, a pesar de los esfuerzos que como país se han realizado, es necesario asumir que el cierre de los planteles educativos, desde nivel básico hasta el posgrado, a causa de la pandemia demostró que nos hace falta camino por recorrer para considerarnos un país con las competencias desarrolladas en cuanto al manejo de las estrategias virtuales para el desarrollo de la educación a distancia se refiere, esto a pesar de que en México se ha hecho presente desde el año 1941 tal y como se muestra en la siguiente figura 1 :

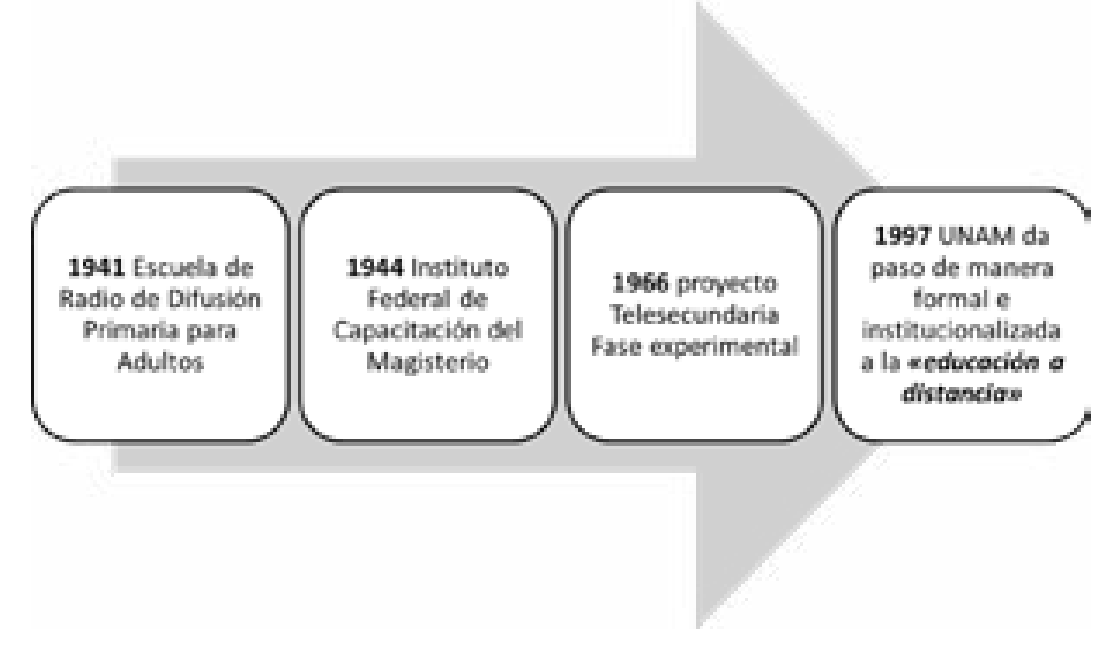

Figura 1. Historia de la ED en México

Fuente: Elaborado a partir de la revisión de la literatura.

La educación a distancia como ya se ha mencionado se puede generar en diferentes estadios, uno de ellos es ambientes virtuales de aprendizaje, concebido, para efecto de la investigación, como el espacio para el aprendizaje que promueve en los estudiantes la adquisición de nuevos conocimientos y experiencias en modalidad a distancia haciendo uso de las Tecnologías de la Información y la Comunicación (Herrera Batista, 2007).

Ahora bien, ante los acontecimientos expuestos sobre la necesidad de brindar atención a los estudiantes en el marco del confinamiento, las IES en México replantearon el desarrollo de sus cursos del ciclo febrero 2020, cuando la Secretaría de Salud implementó el confinamiento, enviando tanto a profesores como a estudiantes a sus hogares. Esta estrategia fue implementada de forma abrupta por lo que las IES, a pesar de contar con sus departamentos o áreas de educación a distancia, se vieron sobrepasadas para brindar el servicio a la totalidad de la matrícula de la modalidad presencial. Ante esta situación, los estudiantes y profesores fueron subsanando la situación en 
la medida de las posibilidades existentes, tanto de conectividad como de equipamiento con el que se contaba para brindar la continuidad de la educación superior.

Desde el punto de vista institucional para la Universidad objeto de estudio es importante seguir brindando educación cumpliendo los estándares de calidad marcados por los organismos tanto nacionales como internacionales; en consecuencia se consideró una prioridad conocer la opinión de los estudiantes en relación a ésta estrategia de atención que desarrollo con el afán de brindarles la atención educativa sin interrupciones a pesar de la contingencia de salud.

Para ello se plantea como satisfacción estudiantil el grado de congruencia entre las expectativas previas de los estudiantes y los resultados obtenidos, con respecto a la experiencia de aprender (Barboza, 2003).

Expuesto lo anterior, se plantea como propósito del presente estudio conocer el grado de satisfacción de los estudiantes en relación a sus cursos durante el ciclo febrero 2020, desarrollados en un ambiente virtual de aprendizaje como estrategia de atención ante la contingencia COVID-19

\section{AMBIENTES VIRTUALES DE APRENDIZAJE}

Un ambiente virtual de aprendizaje es un espacio en el que los actores principales del proceso educativo coinciden para llevar a cabo una interacción visual, auditiva y hasta psicológica en función de un contenido temático determinado para la adquisición de los aprendizajes esperados. Dicho ambiente, incorpora diversidad de recursos previamente diseñados para lograr los objetivos educativos planteados.

Los elementos de los ambientes virtuales de aprendizaje son establecimiento de los procesos comunicativos entre los participantes, medios de interacción, actividades planeadas sobre los contenidos, entorno en el que se llevan a cabo las actividades, tal y como se presenta en la figura 2 .

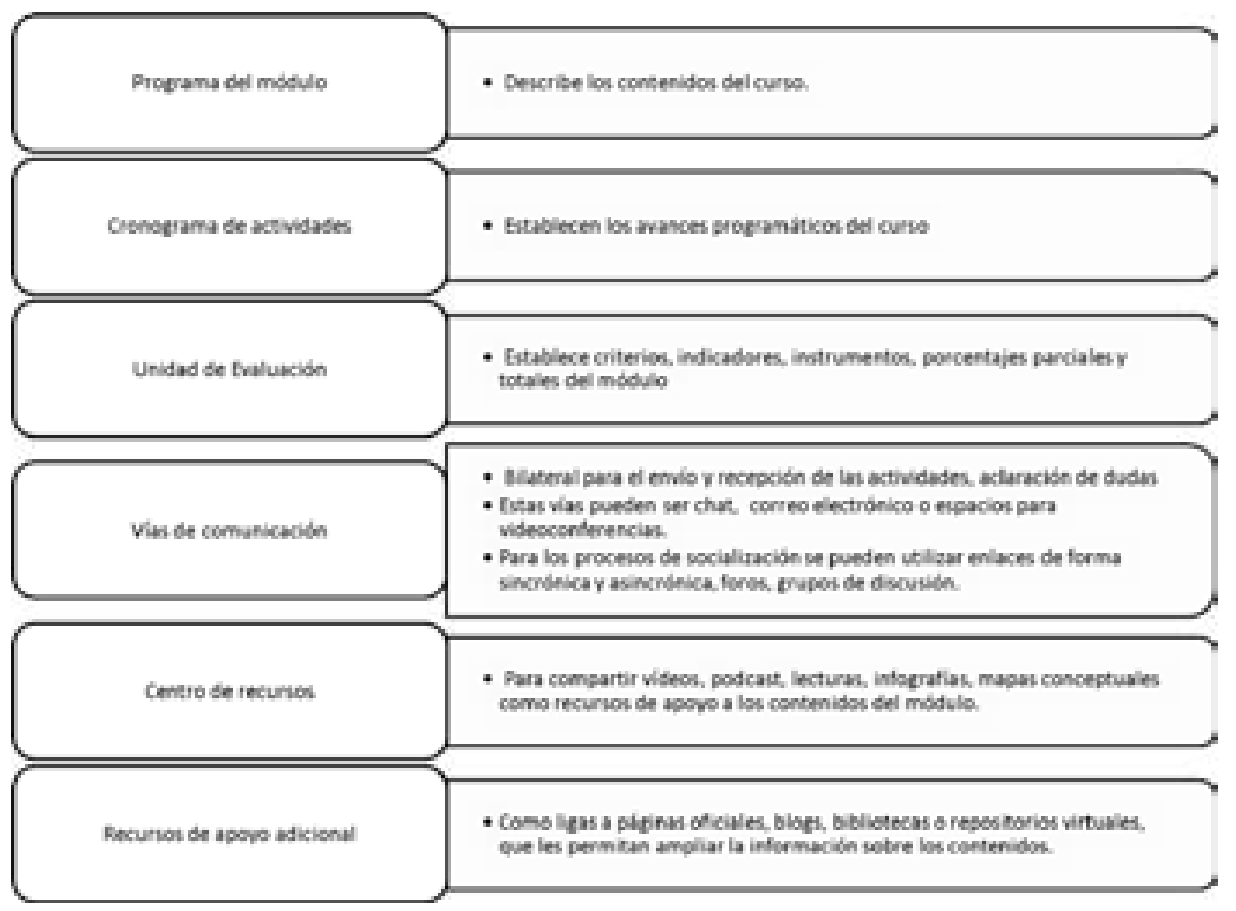

Figura 2. Los elementos de los ambientes virtuales de aprendizaje Fuente: Propia en base a la revisión de la literatura 
Los elementos del AVA, no bastan para lograr la asimilación cognitiva de los contenidos; también se requiere de adecuados materiales didácticos, un contexto adecuado para el desarrollo del aprendizaje, buena actitud y disponibilidad para establecer comunicación asertiva en diferentes medios pre-establecidos o no.

\section{Metodología}

En el presente estudio se optó por una investigación de tipo exploratorio con el propósito de conocer el grado de satisfacción de los estudiantes de la Universidad Autónoma del Carmen, en relación a sus cursos en el ciclo febrero 2020 desarrollados en un ambiente virtual de aprendizaje como estrategia de atención ante la contingencia covid-19. La población fueron los estudiantes matriculados en el ciclo mencionado, la muestra fue no probabilística por conveniencia, lo que permitió un acceso más fácil a los estudiantes seleccionados de las facultades de Ciencias Educativas, Económicoadministrativas, Química, Derecho, Ciencias de la Información, Ciencias de la Salud e Ingeniería es por ello, la heterogeneidad de los participantes. La muestra estuvo constituida por 387 estudiantes, distribuidos de la siguiente manera: 163 estudiantes de la Facultad de Ciencias Educativas, 36 estudiantes de Facultad de Ciencias Económicas-administrativas, 121 estudiantes de la Facultad de Química, de la Facultad de Ciencias de la Información 5, Facultad de Ciencias de la salud 2 y Facultad de ingeniería 1.

La encuesta estuvo constituida por 3 apartados: 1. Datos personales; 2. Satisfacción del estudiante en relación a los cursos, subdivido en: a) Programas y contenidos de los cursos, b) Didáctica del profesor, c) Proceso de evaluación, d) Recursos didácticos y e) Modalidad virtual 3 . Cursos de baja.

\section{RESULTADOS}

A continuación se muestran los resultados de la encuesta aplicada a una muestra de estudiantes de diferentes programas educativos de la Universidad Autónoma del Carmen sobre su satisfacción en cursos ante la contingencia de COVID-19.

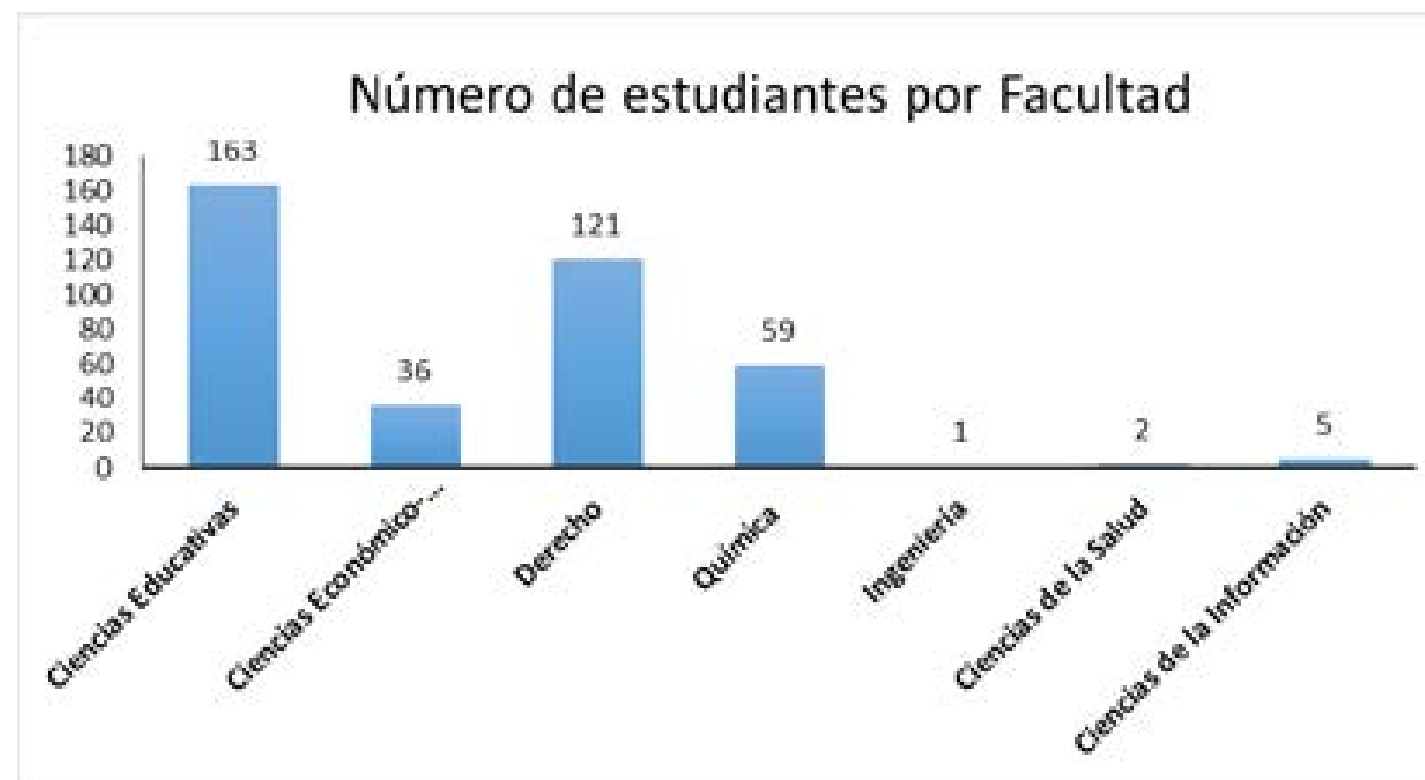

Figura 3. Distribución de los estudiantes encuestados por Facultad 
De acuerdo a la figura 3 , el $42.1 \%$ de los estudiantes encuestados pertenecen a los tres programas educativos (Licenciatura en Lengua Inglesa, Licenciatura en Educación, Licenciatura en comunicación y gestión cultural) de la Facultad de Ciencias Educativas; mientras el $31 \%$ de los estudiantes pertenecen a la Facultad de Derecho de sus dos programas (Licenciatura en Derecho, Licenciatura en Criminología y Criminalística). Asimismo, el 26.9\% restante pertenecen a las Facultades de Ciencias Económico-Administrativas, Química, Ingeniería, Ciencias de la Salud y Ciencias de la Información.

Por otra parte, el $43.1 \%$ de los estudiantes encuestados cargaron de 3 a 5 cursos al inicio de semestre, y el $46.9 \%$ de 6 a 8 cursos.
Además, el $48.6 \%$ y $26.9 \%$, fueron de segundo semestre y cuarto semestre respectivamente, y restante pertenece a los semestres sexto, octavo y décimo.

Si bien, es de gran importancia conocer la satisfacción de los estudiantes universitarios al interactuar con los ambientes virtuales de aprendizaje para la adquisición de habilidades y conocimientos que se desarrollaron en cada uno de sus cursos, también es primordial la experiencia didáctica y la utilización de recursos digitales para el aprendizaje. Es por ello, que basado en la experiencia de los estudiantes ante la Pandemia COVID-19, es necesario valorar la satisfacción en función a la migración de la modalidad presencial a la modalidad en línea, como estrategia de atención académica.

\section{Satisfacción de los estudiantes}

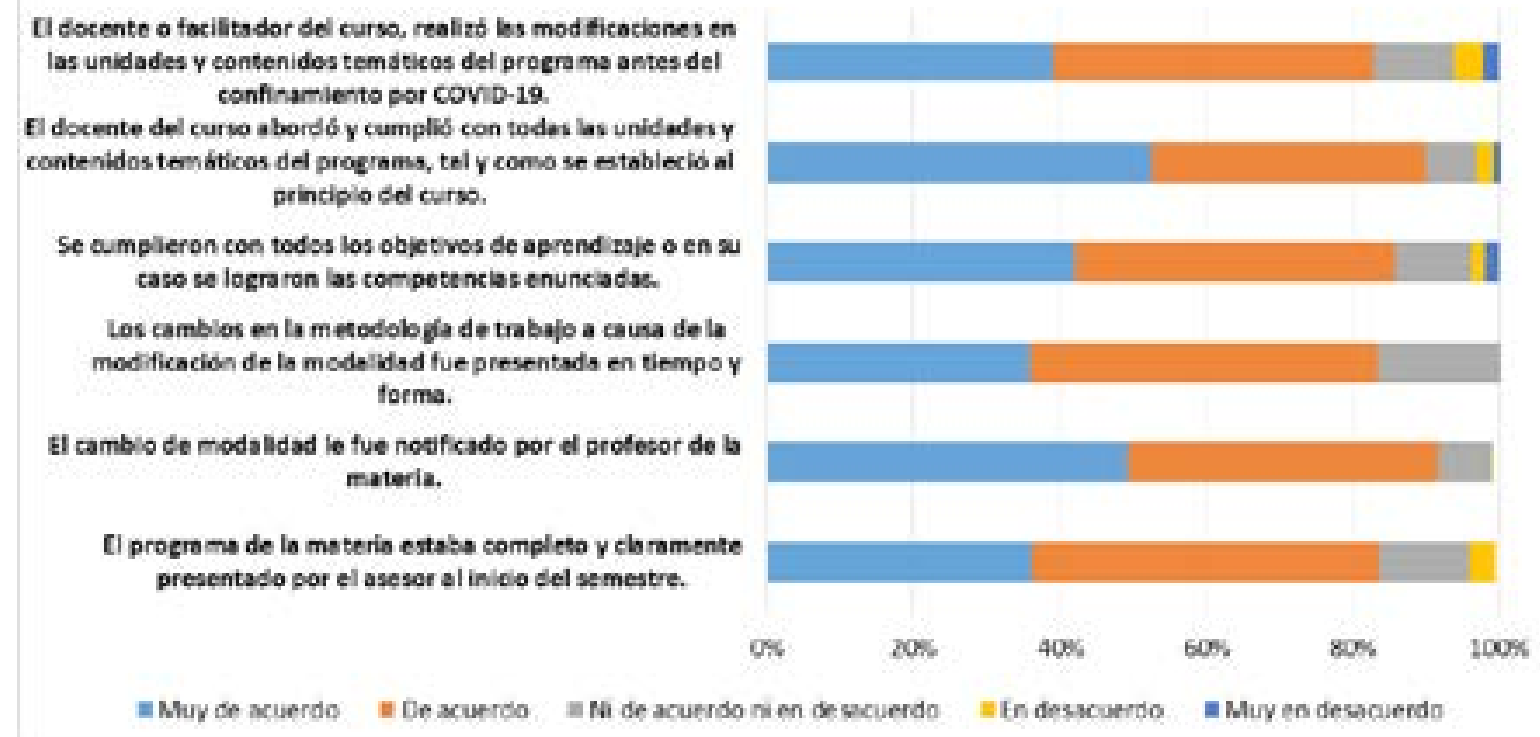

Figura 4. Distribución de la satisfacción de los estudiantes ante la contingencia COVID-19 en relación a los programas y contenidos de los cursos

En la figura 4, se muestra que la satisfacción de los estudiantes en cuanto a la adaptación a los programas y contenidos de los cursos durante la contingencia COVID-19 en el periodo febrero 2020 fue satisfactoria, ya que poco más del $82 \%$ de los estudiantes señalaron que el profesor realizó las modificaciones a las secuencias de aprendizaje de los cursos y las modificaciones de acuerdo a lo establecido de manera inicial. En relación al cambio de modalidad y de metodología de trabajo el $83 \%$ se sintió satisfecho debido a que fue notificado en tiempo y forma sobre la 
metodología por parte del profesor.

Sin bien, debido a la contingencia existió el dilema entre la comunidad docente, si se podían alcanzar los objetivos de aprendizaje o competencias planteados en los cursos por la transición inesperada de la modalidad, de acuerdo a la opinión de los estudiantes encuestados sólo el $2.1 \%$ señaló que no se alcanzaron los objetivos de aprendizaje o competencias a desarrollar, y un 10.3\% prefirieron no opinar al respecto.

Ante la pandemia de covid-19, la didáctica de docente en modalidad virtual debe planearse de manera diferente que la presencial, ya que debe preparar los materiales de apoyo del curso, diseñar actividades de aprendizaje que motiven a los estudiantes y fomentar un ambiente activo que permita la interacción entre los docenteestudiante- estudiante- estudiante.

\section{Satisfacción de los estudiantes}

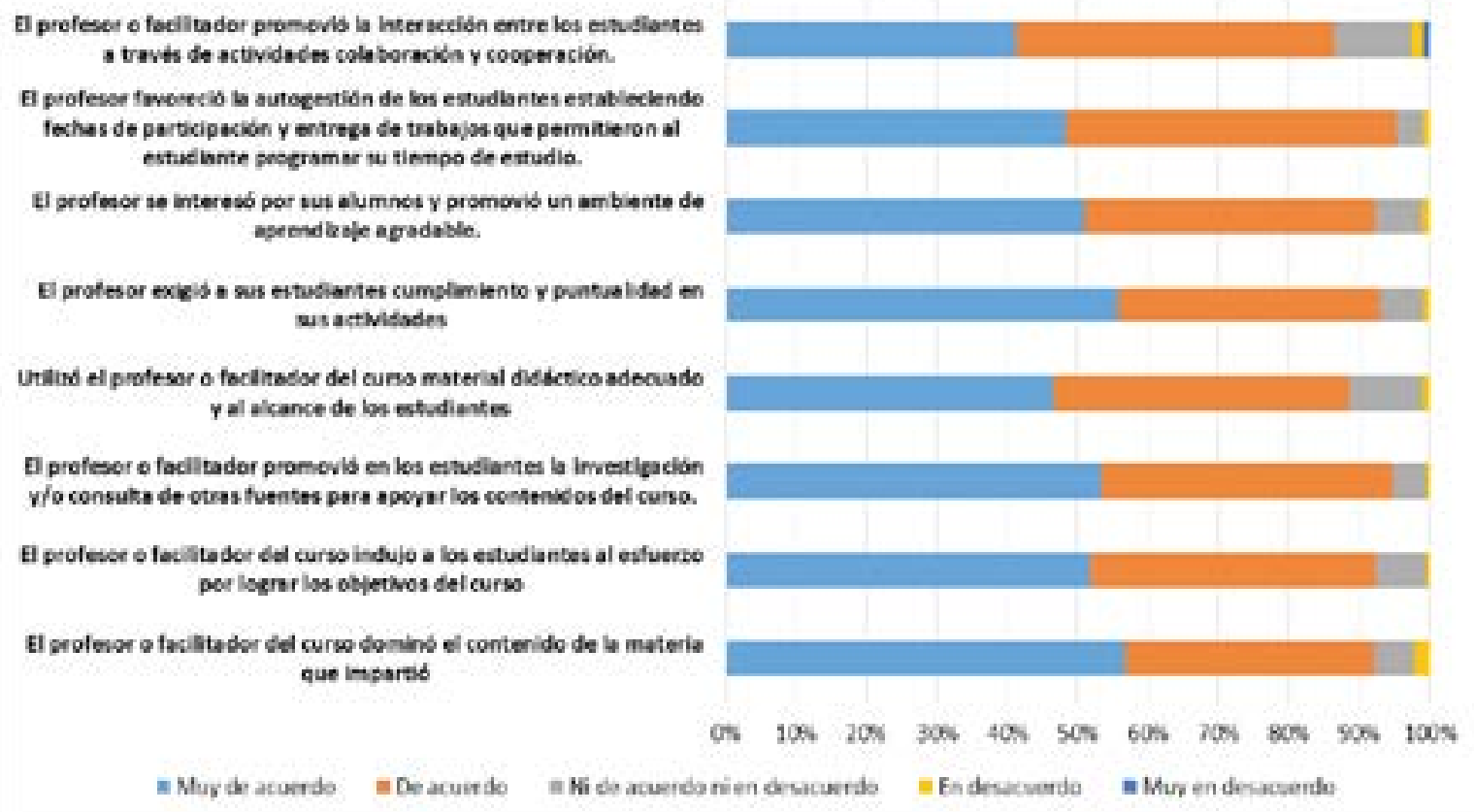

Figura 35Distribución sobre la satisfacción de los estudiantes en relación a la didáctica del profesor

En la figura 5, se puede ver que a pesar del cambio tan repentino de la didáctica del docente a la modalidad virtual, la mayoría de los estudiantes estuvieron satisfechos del desarrollo de sus cursos. Ya que poco más del $80 \%$ de los estudiantes encuestados señalaron que el profesor utilizó el material didáctico adecuado y al alcance de los estudiantes, así como también promovió un ambiente de colaboración y cooperación a través de las actividades de aprendizaje. Sin embargo, no hay que olvidar que el aprendizaje autónomo es una de las características esenciales de la modalidad virtual, lo cual se ve reflejado en promedio, que el $92 \%$ de los estudiantes estuvieron de acuerdo que los profesores de sus cursos promovieron la autogestión, la investigación y responsabilidad de las actividades de aprendizajes propuestas. 


\section{Satisfacción de los estudiantes}

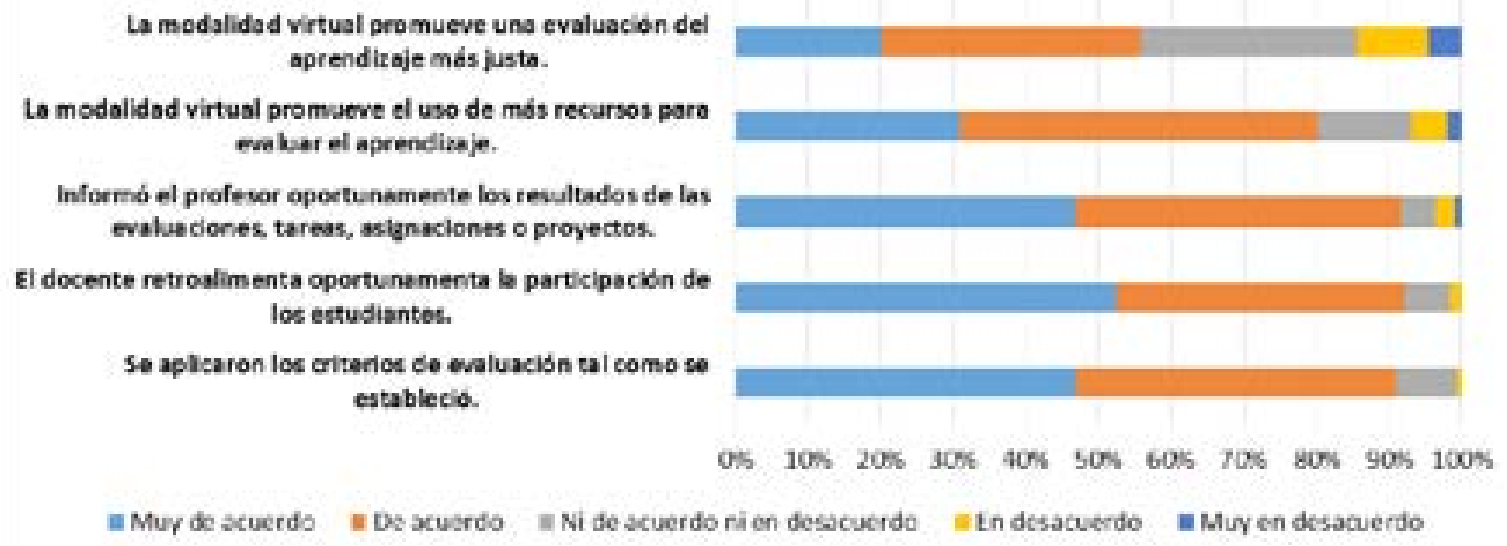

Figura 6. Distribución de la satisfacción de los estudiantes ante el proceso de evaluación en la modalidad virtual

La evaluación del aprendizaje ha sido tema sensible para los estudiantes y más cuando se trabaja en una modalidad virtual. Es importante señalar que muchos docentes de la Universidad no habían trabajado en modalidad virtual, ni mucho menos un acercamiento a la evaluación del aprendizaje en ambientes virtuales de aprendizaje. De acuerdo a la figura 6 , la mayoría de los estudiantes estuvieron satisfecho del proceso de evaluación de sus cursos; mientras un $14.3 \%$ de los estudiantes consideraron que la modalidad virtual no promueve una evaluación del aprendizaje más justa. Sin embargo, el $89 \%$ de los estudiantes señalaron que se aplicaron los criterios de evaluación tal como se estableció en cada uno de los cursos. 


\section{Satisfacción de los estudiantes}

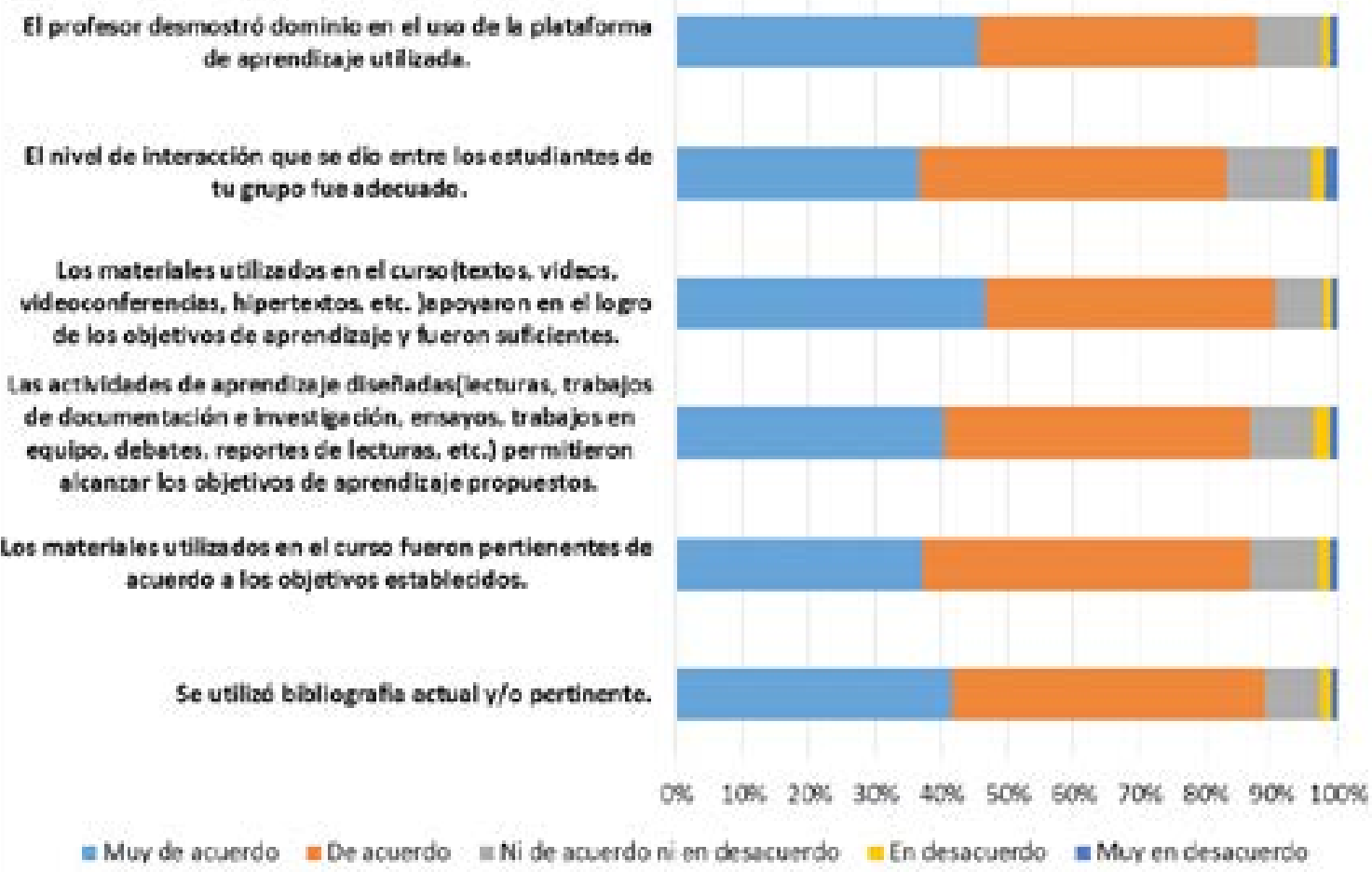

Figura 7. Distribución de la satisfacción de los estudiantes en relación a los recursos utilizados en los cursos en la modalidad virtual

Indudablemente, uno de los consejos efectivos para favorecer el aprendizaje de los estudiantes en la modalidad virtual es la elección de la plataforma y los recursos. La figura7, pone evidencia que los materiales y recursos utilizados en los cursos fueron suficientes para alcanzar los objetivos de aprendizajes o competencias planeados en los cursos. En promedio, el $87.2 \%$ de los estudiantes estuvieron de acuerdo que el profesor tuvo dominio pleno de la plataforma y que los recursos y actividades de aprendizajes propuestas en los cursos en modalidad virtual fueron suficientes para alcanzar los aprendizajes esperados.
El ambiente virtual de aprendizaje favoreció el desarrollo de los cursos presenciales como respuesta a la contingencia por covid-19 en la Universidad Autónoma del Carmen. De acuerdo a la valoración de los estudiantes se obtuvo lo siguiente: 


\section{Opinión de los estudiantes}

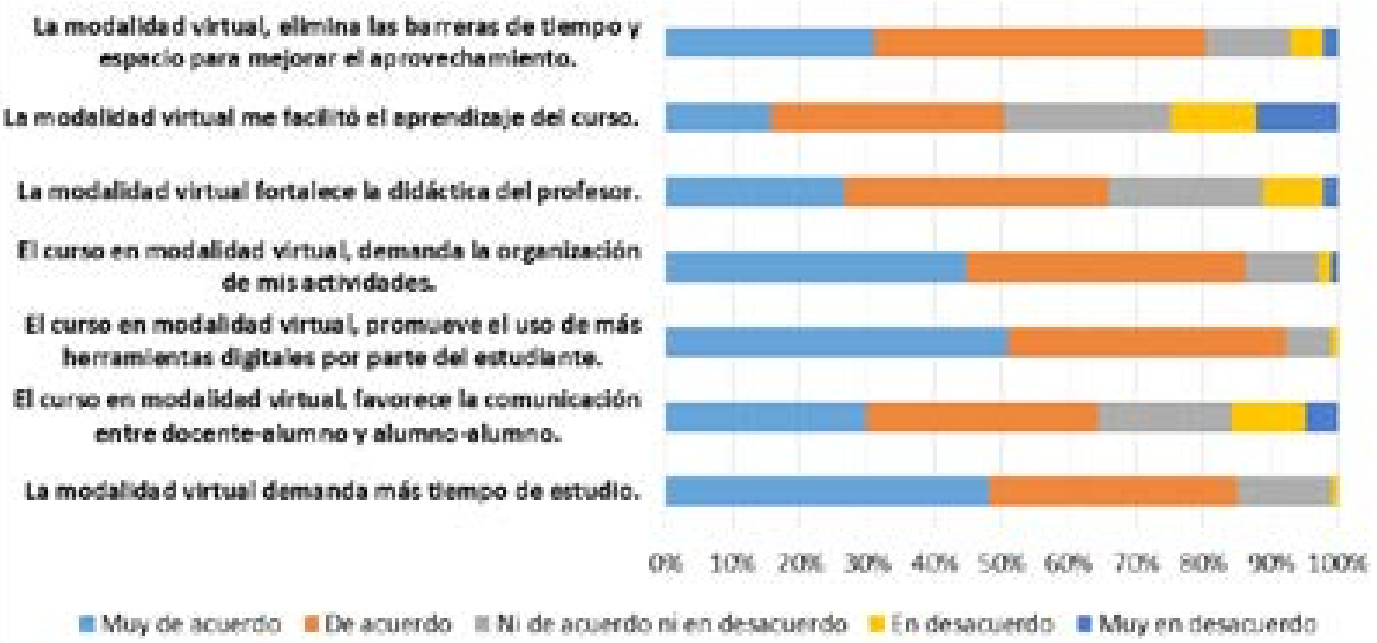

Figura 8. Distribución de la opinión de los estudiantes sobre la modalidad virtual

En la actualidad los ambientes virtuales de aprendizaje representan una herramienta indispensable en el proceso de aprendizaje de los estudiantes universitarios, sin embargo ante la contingencia por covid-19 se tuvo que transitar de manera inesperada de la clase presencial a la virtual. En la figura 8 , se muestra que el $24.8 \%$ de los estudiantes estuvieron en desacuerdo y muy en desacuerdo de que la modalidad virtual facilitó el aprendizaje del curso. Por otra parte, aproximadamente el $63 \%$ de los estudiantes señalaron que los cursos virtuales favorecen la comunicación entre docente-alumno y alumnoalumno; asimismo la mayoría de los estudiantes señalaron que la modalidad virtual fortalece la didáctica del profesor, promueve el uso de más herramientas digitales, la organización de las actividades y demanda más tiempo de estudio, pero que además elimina las barreras de tiempo y espacio para un mejor aprovechamiento en los cursos.

\section{No. de estudiantes}

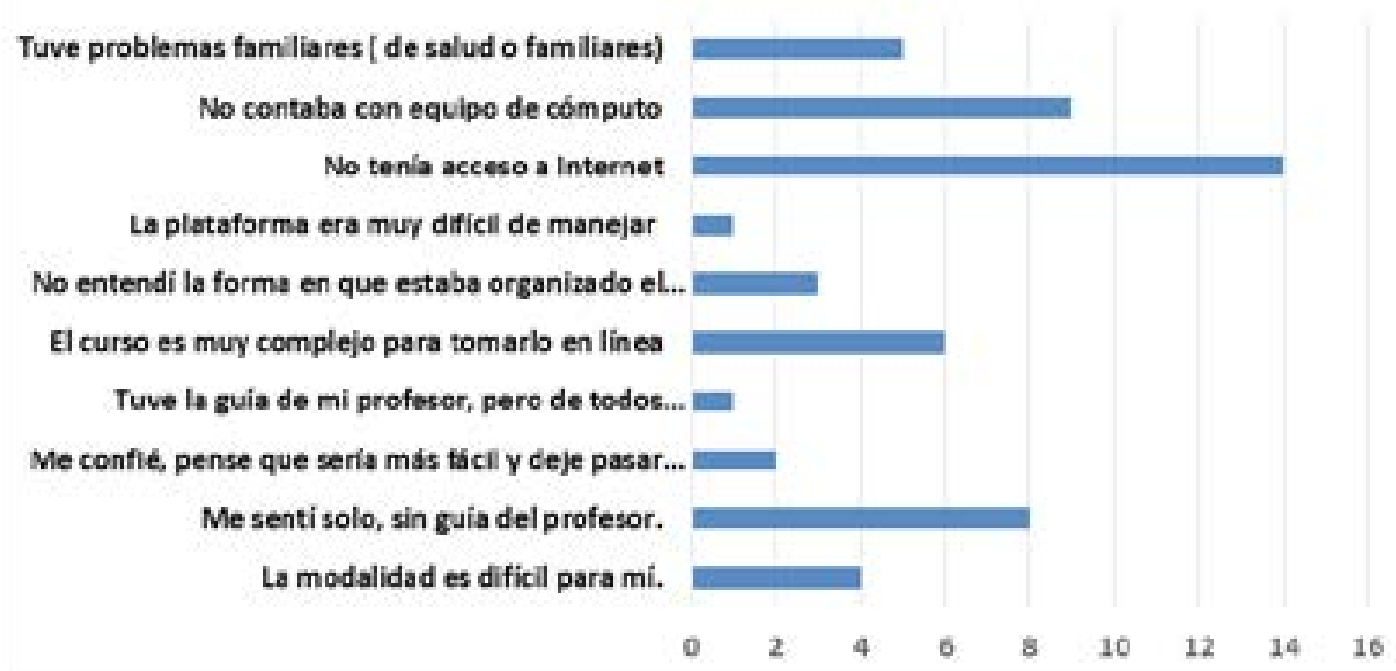

Figura 9. Distribución de las causas más frecuentes de baja en los cursos de modalidad virtual 
Debido al confinamiento los estudiantes tenían la opción de dar de baja algunos de sus cursos del ciclo de acuerdo a sus posibilidades de atención. Sin embargo, sólo el $6.9 \%$ de los estudiantes encuestados se dieron de baja en al menos un curso y correspondían a cursos genéricos, básicos de la carrera y profesionalizante. La figura 9 se puede visualizar que las razones más frecuentes fueron que no contaba con equipo de cómputo y acceso a internet, así como también que se sentía sólo durante el proceso de aprendizaje.

\section{CONCLUSIONES}

De acuerdo al propósito del presente estudio que fue conocer el grado de satisfacción de los estudiantes en relación a sus cursos durante el ciclo febrero 2020, desarrollados en un ambiente virtual de aprendizaje como estrategia de atención ante la contingencia COVID-19. Con el ejercicio de exploración realizado con los estudiantes de nivel superior de la Universidad objeto de estudio, se concluye que fue alto el nivel de satisfacción de los estudiantes en relación a sus cursos que por contingencia covid-19 fue necesario migrar de modalidad presencial a modalidad virtual.

Los esfuerzos de la planta docente para brindar continuidad a la formación de los estudiantes universitarios, sin que el cambio abrupto de modalidad perjudicara el desempeño de ellos, fue satisfactorio. Los procesos de desarrollo y evaluación del curso, así como los materiales utilizados por los docentes durante la migración de sus cursos presenciales a los ambientes virtuales de aprendizaje fueron considerados por los universitarios adecuados.

Por otra parte, a pesar de que parte de la estrategia inicial de apoyo a los universitarios contempló apoyar a los estudiantes que lo solicitaran dar de baja los cursos matriculados en el ciclo febrero 2020, fueron pocos quienes solicitaron esta alternativa, y en su mayoría quienes lo hicieron fue debido a las carencias de equipo de cómputo, acceso a internet o por problemas de carácter familiar que afrontaron al inicio de la pandemia.

A pesar de que las condiciones obligaron a la Institución a desarrollar la modalidad virtual, los profesores, incluidos aquellos quienes se enfrentaron por vez primera a esta contexto, demostraron mediante la adecuación de sus programas de curso, el desarrollo de contenidos, la evaluación objetiva y pertinente, la retroalimentación puntual, el compromiso que la profesión como tal exige en los procesos de formación universitaria.

Indudablemente, en el proceso de aprendizaje o el desarrollo de competencias en la modalidad virtual requiere del compromiso y la autonomía del estudiante para cumplir con los objetivos de aprendizajes esperados, a pesar del cambio abrupto de modalidad el $92 \%$ de los estudiantes estuvieron de acuerdo que los profesores de sus cursos promovieron la autogestión, la investigación y responsabilidad de las actividades de aprendizajes propuestas. Además, parte de las opiniones que se obtuvieron fue un $83 \%$ de los estudiantes expreso satisfacción en relación al cambio de modalidad presencial a virtual y sobre la metodología de trabajo, lo cual evidencia la satisfacción por parte de los estudiantes sobre las propuestas didácticas que tuvieron los docentes en sus ambientes virtuales de aprendizaje.

Por otra parte, la evaluación de los aprendizajes siempreharepresentadounretoparalos docentes universitarios en la educación presencial, ya que se deben diseñar instrumentos de evaluación acorde al modelo educativo por competencias, y más por agregado de la virtualidad. Sin embargo, considerando la poca experiencia de los docentes en modalidad virtual, un $89 \%$ de los estudiantes consideran que los criterios de evaluación fueron implementados de acuerdo a lo que fue establecido en el programa inicial del 
curso y también se dio una evaluación justo en los cursos.

\section{REFERENCIAS BIBLIOGRÁFICAS}

Barboza, J. F. (2003). La satisfacción estudiantil como indicador de la calidad de la educación superior. Investigación Educativa, 7(12), 77-85.

Fernández, M., Herrera, L., Hernández, D., Nolasco, R., \& De la Rosa, R. (2020). Lecciones del Covid-19 para el sistema educativo mexicano. Nexos. Distancia por Tiempos. Blog de Educación.

Herrera Batista, M. A. (2007). Consideraciones para el diseño didáctico de ambientes virtuales de aprendizaje: Una propuesta basada en las funciones cognitivas del aprendizaje. Revista Iberoamericana de Educación. Recuperado de http://www .rieoei.org/deloslectores/1326Herrera. pdf 